Published in final edited form as:

Biomaterials. 2019 October ; 217: 119307. doi:10.1016/j.biomaterials.2019.119307.

\title{
Physical confinement induces malignant transformation in mammary epithelial cells
}

\author{
Yen-Chun Lu ${ }^{\mathrm{a}}$, Tinyi Chu ${ }^{\mathrm{b}}$, Matthew S. Hall ${ }^{\mathrm{a}}$, Dah-Jiun Fuc, Quanming Shid,e, Alan Chiu ${ }^{\mathrm{a}}$, \\ Duo An ${ }^{\mathrm{a}}$, Long-Hai Wang ${ }^{\mathrm{a}}$, Yehudah Pardo ${ }^{f}$, Teresa Southard ${ }^{\mathrm{c}}$, Charles G. Danko ${ }^{\mathrm{b}, \mathrm{c}}$, Jan

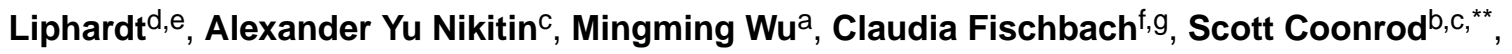 \\ Minglin $\mathrm{Ma}^{\mathrm{a},{ }^{*}}$ \\ aDepartment of Biological and Environmental Engineering, Cornell University, 111 Wing Drive, \\ Ithaca, NY, 14853, USA \\ ${ }^{\mathrm{b}}$ Baker Institute for Animal Health, College of Veterinary Medicine, Cornell University, 235 \\ Hungerford Hill Road, Ithaca, NY, 14853, USA \\ 'Department of Biomedical Science, College of Veterinary Medicine, Cornell University, 930 \\ Campus Road, Ithaca, NY, 14853, USA \\ dBioengineering, Stanford University, 443 Via Ortega Shriram Center, Stanford, CA, 94305, USA \\ eBioX Institute, Stanford University, 318 Campus Drive, Stanford, CA, 94305, USA \\ ${ }^{f}$ Nancy E. and Peter C. Meinig School of Biomedical Engineering, Cornell University, Ithaca, NY, \\ 14853, USA \\ gKavli Institute at Cornell for Nanoscale Science, Cornell University, Ithaca, NY, 14853, USA
}

\section{Abstract}

The physical microenvironment of tumor cells plays an important role in cancer initiation and progression. Here, we present evidence that confinement - a new physical parameter that is apart from matrix stiffness-can also induce malignant transformation in mammary epithelial cells. We discovered that MCF10A cells, a benign mammary cell line that forms growth-arrested polarized acini in Matrigel, transforms into cancer-like cells within the same Matrigel material following confinement in alginate shell hydrogel microcapsules. The confined cells exhibited a range of tumor-like behaviors, including uncontrolled cellular proliferation and invasion. Additionally, 4-6

\footnotetext{
*Corresponding author. ${ }^{* *}$ Corresponding author. Baker Institute for Animal Health, College of Veterinary Medicine, Cornell University, 235 Hungerford Hill Road, Ithaca, NY, 14853, USA. y12347@ cornell.edu (Y.-C. Lu), sac269@ cornell.edu (S. Coonrod), mm826@cornell.edu (M. Ma).

Author contributions

Y.-C.L., S.C, C.D. and M.M. contributed experiment design. Y.-C.L. contributed experiments performance, characterization, data collection, data analysis and manuscript preparation. T.C. contributed the RNA-sequencing data analysis. D.A. contributed the mechanical characterization and in-vivo work. A.C. contributed in-vivo transplantation. L.W. contributed the mechanical characterization. M.S.H. contributed in bead displacement analysis. Q.S. contributed in MCF10A cell modification. T.S. contributed pathological analysis for in-vivo xenograft. D.-J.F. contributed the preparation of DNA sequencing work. All the authors discussed the results and commented on the manuscript.

Conflicts of interest

The authors declare no competing financial interests.

Appendix A. Supplementary data

Supplementary data to this article can be found online at https://doi.org/10.1016/j.biomaterials.2019.119307.
} 
weeks after transplantation into the mammary fad pads of immunocompromised mice, the confined cells formed large palpable masses that exhibited histological features similar to that of carcinomas. Taken together, our findings suggest that physical confinement represents a previously unrecognized mechanism for malignancy induction in mammary epithelial cells and also provide a new, microcapsule-based, high throughput model system for testing new breast cancer therapeutics.

\section{Keywords}

Breast cancer; Physical confinement; Tumorigenesis; Hydrogel

\section{Introduction}

Breast cancer (BC) is the second leading cause of cancer-related deaths in women [1] and its progression is categorized from benign to malignant [2-4]. Ductal carcinoma in situ (DCIS) represents an early, pre-invasive stage of breast cancer in which neoplastic epithelial cells begin to fill the mammary duct [5]. Invasive BC occurs when the neoplastic cells within the duct break through the basement membrane, invade into the neighboring stromal tissues, and begin to spread to other organs [5]. In BC research, the non-malignant MCF10A basal cell line is commonly used to study how normal epithelial cells become transformed into triple negative BC [6] (estrogen receptor, progesterone receptor, and human epidermal growth factor receptor 2 negative [7]). Previous studies have shown that, upon in vitro culture in Matrigel $^{\mathrm{TM}}$ (a reconstituted basement membrane matrix [8,9]), MCF10A cells grow into hollow acinar-like structures which resemble the normal acinar architecture in mammary glands [9]. Additionally, studies have shown that stable incorporation of specific oncogenes into these cells causes severe disruption of the acinar structure, uncontrolled growth, and loss of polarity $[10,11]$.

In the breast, mammary ducts are composed of a thin layer of luminal cells surrounded by myoepithelial (basal) cells which are constrained by a basement membrane (BM). Outside of the BM, collagen fibers and other extra-cellular matrix (ECM) components are secreted by stromal cells, such as fibroblasts, to provide, amongst other things, structural support for the mammary ducts $[12,13]$. However, when the neighboring collagen matrix becomes overly dense, the imposing physical confinement of this matrix on the mammary epithelial cells, is thought to play a role in the transformation of normal mammary epithelial cells to DCIS [13] (Fig. 1a). While the connection between tissue density and malignant transformation has been widely studied, the precise mechanisms linking these two events remains to be fully defined. Previous studies investigating the relationship between mechanics of ECM and tumorigenicity have cultured MCF10A cells in a type I collagen matrix that had been modified by glycation to tune ECM stiffness [14]. Alternatively, collagen has been added directly to Matrigel to increase its stiffness [15]. However, type I collagen is not normally found in the mammary basement membrane matrix [16]. Therefore, adding collagen changes both the composition of the matrix and the density of binding sites, making it difficult to identify the cause of malignant transformation. To alter matrix stiffness without changing the density of binding sites, in another study [16], Matrigel was mixed with alginate, a naturally 
derived hydrogel that lacks adhesive binding sites, in a fixed composition and crosslinked with varying calcium concentrations to control its mechanical properties [16]. In this system, mechanical stiffness could be altered without affecting Matrigel concentration, however, the addition of alginate does not closely parallel the microenvironment that cells normally encounter in vivo.

In order to document the effects of a confined microenvironment on tumorigenicity in a more biologically relevant setting, we developed a model system whereby we embedded MCF10A cells in Matrigel and then encapsulated these cells with Matrigel in alginate shell hydrogel microcapsules. The core-shell encapsulation allowed us to examine how confinement of MCF10A cells within unaltered Matrigel affects the proliferative and migratory potential of these cells. In vitro culture and in vivo graft experiments revealed that the confined MCF10A cells exhibited tumor-like behavior, including uncontrolled growth and formation of carcinomas in immunocompromised mice. Various further control experiments confirmed that the physical confinement was likely responsible for the observed malignancy. Therefore, this core-shell encapsulation would provide a new platform to study confinement on cells in pure ECM and how physical confinement can induce a malignant transformation of mammary epithelial cells.

\section{Materials and Methods}

\subsection{Reagents and materials}

Sterile alginate (UPLVG) was purchased from FMC Biopolymers and dissolved in $0.8 \%$ $(\mathrm{w} / \mathrm{v})$ sodium chloride (Sigma-Aldrich) solution. Matrigel (growth factor reduced with phenol red free, 356237) was purchased from Corning. The crosslinking buffer was prepared as $100 \mathrm{mM}$ calcium chloride (Sigma-Aldrich) solution with $5 \mathrm{mM}$ barium chloride (SigmaAldrich).

\subsection{Cell culture}

MCF-10A mammary epithelial cells were maintained in DMEM:F12 (Invitrogen) supplemented with 5\% (v/v) horse serum (Invitrogen), $20 \mathrm{ng} / \mathrm{mL} \mathrm{hEGF}$ (Invitrogen), 0.5 $\mu \mathrm{g} / \mathrm{mL}$ hydrocortisone (Sigma-Aldrich), $10 \mu \mathrm{g} / \mathrm{mL}$ insulin (Sigma-Aldrich), $100 \mathrm{ng} / \mathrm{mL}$ cholera toxin (Sigma-Aldrich), and 50 units $/ \mathrm{mL}$ penicillin and $50 \mu \mathrm{g} / \mathrm{mL}$ streptomycin (Invitrogen). Madin Darby Canine Kidney (MDCK) cells were cultured in Dulbecco's modified Eagle's medium (DMEM) with $4.5 \mathrm{mg} / \mathrm{mL}$ glucose, $1 \mathrm{mM}$ sodium pyruvate (Invitrogen) supplemented with 10\% (v/v) heat-inactivated fetal bovine serum (FBS) (Invitrogen), $5 \mathrm{mM} \mathrm{L}$-glutamine (Invitrogen), 50 units $/ \mathrm{mL}$ penicillin and $50 \mu \mathrm{g} / \mathrm{mL}$ streptomycin (Invitrogen). MCF10DCIS.COM mammary cancer cells were maintained in DMEM:F12 supplemented with $5 \%(\mathrm{v} / \mathrm{v})$ horse serum and $50 \mathrm{units} / \mathrm{mL}$ penicillin and 50 $\mu \mathrm{g} / \mathrm{mL}$ streptomycin. Human primary mammary epithelial cells were grown in Mammary Cell Basal Medium (ATCC PCS-600-030) supplemented with the Mammary Epithelial Cell Growth Kit (ATCC PCS-600-040). These cells were incubated at $37^{\circ} \mathrm{C}$ in $5 \% \mathrm{CO}_{2}$. 


\subsection{Immunohistochemistry \& immunofluorescent}

Both in vitro and in vivo samples were fixed by $10 \%$ (v/v) formalin in PBS before processing for paraffin-embedded sectioning by Cornell Histology Core Facility or whole mount staining. In addition, the paraffin sections were stained with hematoxylin/eosin by the core facility at Cornell University. Paraffin sections with $10 \mu \mathrm{m}$ thickness were processed by de-paraffin and rehydration procedure under sequential incubation and washing steps: xylene, $100 \%$ ethanol, 95\% (v/v) ethanol, 70\% (v/v) ethanol and water before immunohistochemistry or immunofluorescent staining. In immunohistochemistry, the rehydrated section was first incubated with citrate buffer for antigen retrieval before blocking in $10 \%(\mathrm{v} / \mathrm{v})$ normal goat serum and $1 \%(\mathrm{v} / \mathrm{v})$ bovine serum albumin (BSA) in Tris-buffered saline (TBS) for 2 hours at room temperature (RT). The primary antibodies in $1 \%(\mathrm{v} / \mathrm{v}) \mathrm{BSA}$ in TBS were incubated at $4{ }^{\circ} \mathrm{C}$ overnight before the peroxidase block with $0.3 \%$ (v/v) hydrogen peroxide for 15 minutes and biotinylated secondary antibody incubation. We incubated the samples with NovaRED (SK-4805, Vector labs) as an enzyme substrate for 5-10 minutes and Hematoxylin as a counter stain. Finally, the sections were dehydrated by incubating in $75 \%(\mathrm{v} / \mathrm{v})$ ethanol, $95 \%(\mathrm{v} / \mathrm{v})$ ethanol, $100 \%$ ethanol and xylene before mounting in cytoseal XYL. The slides for immunochemistry and H\&E staining were imaged by Aperio Scanscope (CS2) by 40x and processed by Aperio eSlide Manager. For immunofluorescent staining, the rehydrated sections or fixed samples for whole-mount staining were washed by PBS and incubated in $1 \%(\mathrm{v} / \mathrm{v})$ BSA in phosphate buffered solution (PBS) before applying the primary antibody in 1\% (v/v) BSA in PBS for 30-60 minutes at RT. After washing with PBS three times, the secondary antibodies (sometimes mixed with phalloidin for F-actin staining) in PBS were incubated for 30-60 minutes at RT. Lastly, the fluorescently stained slides were mounted in Fluoroshield with DAPI (4',6-Diamidino-2Phenylindole, Dihydrochloride). The fluorescent images were captured by a Zeiss LSM710, LSM880 confocal microscope, or Olympus FV1000 confocal microscope.

\subsection{Animals}

We purchased 8-week old Scid-Beige female mice (CBSCBG-F, C.B-Igh-1b/GbmsTacPrkdc ${ }^{\text {scid }}$-Lyst ${ }^{b g}$ N7) from Taconic Farms for xenograft experiments. The xenograft transplantation procedure was approved by the Cornell Institutional Animal Cate and Use Committee.

\subsection{D culture and invasion assay}

Bulk Matrigel samples were prepared by mixing cells with Matrigel and dripping them into a 96 well-plate or petri dish as a comparison with microcapsules. The medium was changed every 2-4 days until the 40-day end point. For the invasion assay, the encapsulated MCF10A cell aggregations were collected from microcapsules by dissolving the hydrogel layer, and the MCF10A acini were obtained from bulk Matrigel. Before being embedded in collagen gel, the aggregates and acini were washed by cold PBS to remove alginate or Matrigel residues. Type I collagen from rat tail was dissolved in $0.1 \%(\mathrm{v} / \mathrm{v})$ acetic acid at $4{ }^{\circ} \mathrm{C}$ for 3 days at the desired concentration $(5 \mathrm{mg} / \mathrm{mL})$. It was diluted with growth medium and neutralized by $1 \mathrm{~N}$ sodium hydroxide at $4{ }^{\circ} \mathrm{C}$ at a final concentration of collagen of 1.5 
$\mathrm{mg} / \mathrm{mL}$ before mixing with cells or aggregations. The collagen gel/fibers were formed at 37

${ }^{\circ} \mathrm{C}$ for $30 \mathrm{~min}$.

\subsection{Cell encapsulation}

Cells were diluted in pure reconstituted basement membrane matrix (Matrigel ${ }^{\mathrm{TM}}$ ) to the desired cell density. The cells were encapsulated in sterile alginate (UPLVG FMC

Biopolymers) crosslinked with calcium chloride mixed with barium chloride by a two fluidic electrostatic co-spraying technique under an electrical voltage ranging from 5.8 to $7.2 \mathrm{kV}$ [17]. Microcapsules with different number of cells in the Matrigel core were hand-picked and cultured in 96 well plate for subsequent studies.

\subsection{Xenograft preparation}

The encapsulated MCF10A cells were extracted from microcapsules by alginate lyase to dissolve the hydrogel layer. Half of the cell aggregates were incubated in $0.25 \%$ Trypsin with 2.21 mM EDTA in Hank's Balanced Salt Solution (HBSS) to obtain single MCF10A cells. The cell number of MCF10A aggregates was estimated by the measurement of dissociated single cells. For control groups, acini were prepared by culturing MCF10A cells in bulk Matrigel for 40 days. MCF10A cells and MCF10DCIS.COM cells were detached from culture flasks by $0.25 \%$ Trypsin with $2.21 \mathrm{mM}$ EDTA in HBSS. For xenograft experiments, all the cells/aggregates were spun down in $1.5 \mathrm{~mL}$ microcentrifuge tubes and suspended in $100 \mu \mathrm{L}$ Matrigel solution before injection. One million cells in Matrigel were injected into mammary fat pad of 10 week-old female Scid-Beige mice via a 26G needle (BD).

\subsection{Clinical anatomic pathological analysis}

The xenograft tumors collected from mice were fixed by $10 \%$ formalin in PBS before embedding in paraffin for sectioning. The H\&E staining slides were analyzed by diagnostic histology laboratory and stem cell pathology unit at Cornell University. The tumor grade was determined by the Nottingham grading system $[4,18]$.

\subsection{Microscopy and image analysis}

The hydrogel capsules were observed and imaged by an EVOS AMF4300 imaging system. The fluorescent images were obtained through the EVOS inverted fluorescent microscope, Zeiss LSM710 confocal microscope operated by ZEN software v. 2010, Carl Zeiss, and Olympus FV1000 confocal microscope. All fluorescent images were processed using ImageJ.

\subsection{Statistical analysis}

All quantification data are presented as mean \pm SEM (standard error of the mean) with at least three independent replicates, and the sample size " $\mathrm{n}$ " in each experiment is given in the legend of each figure. In statistical analysis, all the $\mathrm{p}$ values were calculated by Student's $t$ tests followed by a Mann-Whitney test or two-way ANOVA followed by a Tukey post hoc test using Prism 7 or BMP. In addition, all the figures were created in Prism 7. (N.S.: nonsignificant difference, ${ }^{*} \mathrm{p}<0.05,{ }^{* *} \mathrm{p}<0.01$ and $\left.* * * \mathrm{p}<0.001\right)$. 


\section{Results}

\subsection{Core-shell microcapsules simulating physical confinement}

In an effort to mimic the confining effect of high density collagen fibers on the mammary epithelium in vivo, here, we developed a core-shell hydrogel microcapsule platform that contains a core of Matrigel-embedded MCF10A cells surrounded by an outer alginate layer (Fig. 1b). The microcapsules were produced by a two fluidic electrostatic co-spraying technique (Fig. 1c) at a production rate (from 120 to 4,000 capsules/min depending on capsule size) with nearly mono-disperse spherical size (Fig. 1d-f) and tunable core diameter $(\sim 100-600 \mu \mathrm{m})$ [17]. The core, containing MCF10A cells in soft Matrigel ( 450 Pa [19], Fig. 1g, red Matrigel, blue Hoechst stained cells), is separate from the stiffer alginate shell ( $48.4 \mathrm{kPa}$, Fig. S1 in the Supporting Material) which mimics the mechanical modulus of breast cancer tissue [20]. In addition to providing a soft environment, the Matrigel supports mammary epithelium morphogenesis. When in Matrigel, single MCF10A cells proliferate into small aggregates and, following apoptosis of the inner mass, form hollow structures called acini [13]. In vitro, integrin $\beta 1$ is localized on the surface of the acini, suggesting hemidesmosome formation, a key element of acinar formation (Fig. 2a). In contrast, within the confinement of an alginate shell, multiple MCF10A cells failed to form acini in Matrigel and, instead, underwent uncontrolled growth as demonstrated by the disruption of integrin $\beta 1$ surface localization (Fig. $2 b$ ). To test whether the observed effects on acini formation were not simply due to cellular overcrowding, we cultured MCF10A cells with different initial cellular concentrations in Matrigel for 40 days and measured the percentage of acini formation as well as the size of the acini. We found that, regardless of the initial cellular concentration, the proportion of MCF10A cells that formed acini remained the same, with only the size of the acini changing (Fig. S2). Although these data suggested that the cellular concentration is likely not a key determinant of the observed malignant growth within the microcapsules, we nevertheless used only single cells for the physical confinement experiments in order to simplify the model. When single MCF10A cells were confined in the microcapsules, the cells again grew uncontrollably (Fig. 2c), eventually breaking the alginate layer (Fig. S3). These results suggest that physical confinement may disrupt the mammary morphogenesis by uncontrolled growth.

To test the hypothesis that decreased oxygen and nutrient diffusion across the microcapsule hydrogel layer may be the cause of the observed proliferative effects [21], we developed a "sandwich" assay to control for the effect of diminishing diffusion. In this assay, cells were embedded in Matrigel (Diffusion coefficient $1.0 \times 10^{6} \mu \mathrm{m}^{2} / \mathrm{h}$ [22]) covered by a layer of alginate (Diffusion coefficient $2.23 \times 10^{6} \mu \mathrm{m}^{2} / \mathrm{h}$ [23]) crosslinked in the same way and having a similar thickness to that of the microcapsules to simulate the mass diffusion in microcapsules. Results showed that, similar to Matrigel alone, polarized and growth-arrested acini structures were formed after 40 days of culture in the "sandwich" model (Fig. S4). Since the mass transfer in the sandwich assay being one-dimensional was similar to or worse than the three-dimensional mass transfer in the core-shell microcapsules, the mass transfer limitation could not be responsible for the observed proliferative effects observed in the capsules. Furthermore, by increasing the diameter of the core to $600 \mu \mathrm{m}$ (see Fig. $5 \mathrm{~g}$ ), the mass diffusion is decreased in the capsules, however, the MCF10A could still form acini. 
Together, we could eliminate the factor of mass diffusion in the observed malignant transformation. Since the large-core capsules were made using the same calcium/barium ions and high voltages, it may also be concluded that the ions or high voltage unlikely play any significant roles in the observed malignant transformation. Lastly, we confirmed there was no significant mixing of Matrigel and alginate hydrogel at the core-shell interface in the microcapsules by using immunofluorescent staining for laminin and fluorescent alginate (Fig. 1g); and even in a bulk mixture of Matrigel and alginate, the MCF10A cells still formed acini (Fig. S5), excluding the possibility that the mixing caused the malignancy in microcapsules. Taken together, these in vitro experiments support the hypothesis that physical confinement causes phenotypic differences in MCF10A cells.

\subsection{Confinement increases cell proliferation, reduces apoptosis, and promotes an epithelial to mesenchymal transition phenotype}

To more thoroughly characterize the phenotypic changes brought on by physical confinement, we performed indirect immunofluorescence using antibodies against a proliferation marker, Ki67, and an apoptosis marker, caspase-3. Results showed that, compared with cells in bulk Matrigel, confined cells exhibited a higher proliferative signal and lower apoptosis, potentially explaining the lack of lumen formation in microcapsules (Fig. 3a-b). Moreover, as with integrin $\beta 1$, we found that integrin $\beta 4$ localization was also disrupted (Fig. 3c), further suggesting that higher proliferation and lower apoptosis might be induced by the disruption of integrin $\beta 1$ and $\beta 4$ signaling.

A key characteristic of malignant transformation and invasion is the epithelial-mesenchymal transition (EMT) in which epithelial cells assume mesenchymal or fibroblast-like behavior with reduced intercellular adhesion and increased cell motility [24]. We found that physical confinement of MCF10A cells facilitated a key feature of the EMT, which is the loss of Ecadherin surface expression (Fig. 3d). To further investigate the ability of confinement to promote the EMT, the invasiveness of confined cells was measured through an invasion assay (Fig. 3e). After culturing in type I collagen gel for 9 days, $83 \%$ of the total aggregates which were collected from microcapsules grew and migrated into the collagen matrix. By contrast, the majority of the acini from bulk Matrigel ( 98\%) remained stable without proliferation (Fig. 3f). Similar behavior was observed when the aggregates or acini were reembedded in Matrigel (Fig. S6). Moreover, E-cadherin was absent from the microcapsulederived aggregates during the invasion assay and integrin $\beta 1$ was expressed throughout the invasive cluster. By contrast, integrin $\beta 1$ was localized at the periphery of the acini (Fig. 3e). These results suggested that physical confinement may have transformed the MCF10A into cells with cancerous properties.

When we collected the confined cells from microcapsules and re-cultured them in a cell culture flask, these cells (i.e. physically confined cells or MCF10A-PC) maintained the tumor-like behavior, such as rapid growth and invasion into bulk Matrigel, even after 6 passages (Fig. S7). This result suggests that physical confinement not only transforms the confined cells into an invasive state, but also maintains the confinement-induced effects on cell phenotype for at least 6 passages, potentially due to lasting epigenetic changes in gene expression. We also examined the effect of physical confinement on a cell line that models 
pre-invasive DCIS breast cancer (MCF10DCIS.COM [25] cells, Fig. S8), on human primary mammary epithelial cells (hPMECs, Fig. S9), and on kidney epithelial cells (MDCK, Fig. S10). These cells all responded to the confinement but in different ways. For example, the MCF10DCIS.COM cells displayed accelerated growth, the hPMECs showed disruption of the mammary epithelium morphogenesis, and MDCK exhibited increased apoptosis.

\subsection{RNA sequencing suggests that physical confinement activates insulin signaling and insulin-like growth factor pathways}

In order to better understand the mechanisms by which confinement induces tumorigenesis, we analyzed gene expression patterns in the confined cells using RNA-seq. We prepared poly-A selected RNA-seq data for four different groups; confined MCF10A cells, which were cultured in microcapsules for 40 days, MCF10A, MCF10DCIS.COM cells, and MCF10A-PC cells at the 9th passage from bulk Matrigel using the same culture conditions as the confined cells. Results show that approximately 8000 genes are differentially expressed (adjusted $\mathrm{p}$ value $<0.01$ ) in confined cells compared to those from MCF10A grown in bulk Matrigel (Fig. 4a-b). In MCF10DCIS.COM and MCF10A-PC cells grown in bulk Matrigel, around 8000 and 3000 genes are differentially expressed compared to the control MCF10A cells, respectively (Fig. S11). Without physical confinement, the MCF10A-PC cells (9th passage) maintained differential expression from normal MCF10A cells in bulk Matrigel (Fig. S12). Lastly, we found that 4500 genes were differentially expressed between MCF10A cells that had been released from confinement for 24 hours prior to RNA extraction when compared to the control MCF10A cells (Fig. S13). These results suggest that confinement of MCF10A cells into microcapsules induced long term epigenetic changes in gene expression.

GO enrichment analysis [26] of these samples identified $~ 161$ potential signaling pathways that were altered by culturing the MCF10A cells in microcapsules (Table S1). Among these pathways, we inferred two possible pathways that promote cell proliferation and prevent apoptosis under physical confinement. The insulin/insulin-like growth factor (IGF) pathway and the mitogen activated protein kinase/MAP kinase cascade (MAPK/MAP) pathway. In order to confirm the activity of these two pathways in the confined MCF10A experimental groups we carried out a range of drug and antibody inhibition studies. Results (Figs. S14S17) show that these pathways appeared to play a direct role in the proliferation of the confined MFC10A cells. Our findings also support the hypothesis that disruption of hemidesmosome formation may induce the IGF type I receptor (IGF1R) binding to integrin $\beta 4$, thus promoting the malignant phenotype [27] (Fig. S18 and details in supplemental information).

\subsection{Confinement restricts matrix fluctuation to disrupt acini formation}

Next, to better understand how physical confinement by microcapsules might affect ECM remodeling, we prepared microcapsules in which the MCF10A expressed EGFP and the Matrigel matrix was tagged with fluorescent microbeads (red). This approach enabled analyzing fluctuations in the matrix that were caused by cellular traction forces and movement (Fig. 5a-b). Time-lapse images were then taken to simultaneously track cell movement and bead displacement using Matlab (Fig. S19). We found that, immediately after 
encapsulation, there was no significant difference between cell movements in the bulk Matrigel group when compared to the cells contained within the microcapsules (Fig. 5c). However, under confinement, matrix fluctuation was restricted, and bead displacement was decreased in the microcapsule group when compared with the bulk group (Fig. 5d). This result suggested that the restricted matrix fluctuation might hinder hemidesmosome formation which could further promote integrin $\beta 4$ and IGF1R [27] complex formation (Fig. $5 e)$. Such an outcome fits well with our RNA-seq data and could explain how physical confinement transforms MCF10A cells.

\subsection{The effect of confinement diminishes when the core diameter increases}

We found that the observed confinement effect depends on cell position in the Matrigel core with the cell growth rate being inversely proportional to the distance between the confined cell and the alginate shell (Fig. 5f). Additionally, we found that increasing the diameter of the Matrigel core actually decreased the growth of confined MCF10A cells. For example, we found that, when the core size increased to $500 \mu \mathrm{m}$ in diameter, the confined cells would grow into small aggregates devoid of luminal structures and reminiscent of pre-malignant breast cancer (Fig. S20). When the core size reached $600 \mu \mathrm{m}$, the confined cells formed hollow acini in capsules, which is similar to that formed by non-confined cells. In the largecore capsules, the MCF10A cells formed growth-arrested, polarized acinar structures and expressed high levels of E-cadherin and localized integrins, suggesting hemidesmosome formation in these structures is more similar to normal acini (Fig. $5 \mathrm{~g}$ ). This result suggests that the effect of physical confinement on cellular growth is inversely proportional to the distance between confined cells and the alginate shell (See discussion and supplemental information), and when the size of core is sufficiently large (e.g. $\sim 600 \mu \mathrm{m})$, the effect of physical confinement nearly vanishes.

\subsection{Confined cells form carcinomas in Scid-Beige mice}

Lastly, to verify that the malignant characteristics observed in vitro were indicative of a true malignant transformation, we tested whether the confined MCF10A cells could form tumors in immunodeficient Scid-Beige mice (which lack T and B lymphocytes and contain defective cytotoxic T cells, macrophages, and natural killer cells). Five different types of cell preparations were injected into the mammary fat pad of immunocompromised mice: confined MCF10A cell aggregates from microcapsules (CMA), dissociated cells from the confined MCD10A cell aggregates in suspension (DCMA), MCF10A acini from bulk Matrigel, MCF10A cells in suspension and MCF10DCIS.COM cells (which, as opposed to MCF10A cells, form tumors in immunodeficient mice) in suspension. For the xenografts, cell aggregates were collected, suspended in $100 \mu \mathrm{L}$ Matrigel, and $\sim 1 \times 10^{6}$ cells were injected into the mammary fat pad tissue using a 26G needle as described in the Materials and Methods and previously [28,29]. After 4-6 weeks, the acinar and MCF10A single cell groups did not form tumors in mice, however, the other three groups (CMA, and DCMA as well as MCF10DCIS.COM) all formed palpable masses in the mice (Fig. 6a). We note that we did not remove skin and hair from the negative control groups because lesions in these groups were either not present or were so small that they could not be dissociated from the skin. Therefore, weight for negative control groups was given a value of zero. For the rest of the groups, these masses were weighed (Fig. 6b), fixed and embedded for histological 
analysis using hematoxylin and eosin and for immunohistochemistry using antibodies against the differentiation markers, p63 for myoepithelial cells, and cytokeratin for luminal cells (Fig. 6c). Based on histologic pattern, mitotic rate and the amount of necrosis (Nottingham grading system [4,18], Figs. S21-22), a pathologist sorted the tumor masses into three grades: low grade (I), intermediate grade (II), and high grade (III). Results from this blinded study show that the confined cell groups (CMA and DCMA) and the control MCF10DCIS.COM group were scored as either intermediate (II) and high grade (III) carcinomas (Fig. 5d). Furthermore, Integrin $\beta 1, \beta 4$ and E-cadherin were also characterized for these samples. (Fig. S23).

\section{Discussion}

The effect of confinement on cellular behavior has been a topic of great interest and studied by using microchannels [30,31], interpenetrating network matrix [15,16,32] and hanging drop plate [33]. However, controversy exists on how the confinement affects the malignant transformation; compounding factors such as irradiation for gel crosslinking and lacks of native cell-adhesion sites from synthetic polymers can complicate the studies. In the coreshell microcapsule platform, unlike previous systems where the cells were in direct contact with the confining wall or matrix, the cell-contacting matrix (i.e. the Matrigel core) and the confinement (i.e. the alginate shell) are decoupled. This allows the study of confinement without altering the natural, cell-contacting matrix and mimics the confinement effect of dense stromal tissue on the mammary epithelium [34,35]. MCF10A cells seeded in Matrigel within microcapsules grew faster and resulted in larger aggregates after 3 days compared to cells grown in bulk Matrigel. After a total of 6 days in the microcapsules, signs of uncontrolled growth in the microcapsule group were apparent (Fig. S24). Moreover, when fully formed acini were collected from bulk Matrigel at day 40 and re-encapsulated, we observed a similar result on the confined acini. Although each acinus was in a growtharrested state, the polarized structure was disrupted in microcapsules and the cells filled the core and eventually escaped the microcapsules completely, suggesting that physical confinement can also successfully transform MCF10A cells after they have fully differentiated into acinar epithelial cells (Fig. S25). These observations of high proliferation and invasion of confined cells are consistent with an earlier report that the physical confinement from hollow microcapsules could enhance proliferative properties of cancer cells by pressure buildup [36] and water efflux [37,38].

Additionally, we would like to emphasize the "confinement effect" described in this work is unique from the "stiffness effect" reported previously. First, the cells were cultured in unaltered Matrigel whose intrinsic stiffness remained unchanged as opposed to previous cases where the matrix stiffness was changed by means such as chemical blending $[15,16]$. Second, the confinement effect was also different from the stiffness effect observed on 2D composite hydrogel [39-41] where a thin layer of a matrix (ex. Matrigel, fibrin, collagen) was attached to the surface of a stiff substrate (ex. glass, plastic) in a slab geometry. In those systems, the proximity of the stiff boundary causes the cells to sense a greater "effective stiffness" than that of the matrix by impeding gel displacements by cell-generated forces. However, the slab geometry of these systems causes the increase in stiffness to be directional, toward the stiff interface and the effect exists only when the distance to the stiff 
boundary is sufficiently small ( $10 \mu \mathrm{m}$ depending on matrix property) [42-45]. In contrast, our "3D confinement" system imposes stiff boundaries in three and all dimensions. As the cells grow in the 3D confined space, they displace and compact ECM, and the collective action of many cells exerting force allows for the cell aggregate at large to experience a greater effective stiffness than that of the local biopolymer matrix. This multicellular confinement effect allows for a greater "effective stiffness" to be experienced for even those cells that are far (on the order of $100 \mu \mathrm{m}$ ) from the boundary and would not experience greater effective stiffness if working in isolation.

The ability of MCF10A cells to differentiate into acini is thought to depend on hemidesmosome formation [46,47]. Hemidesmosomes are important connections between the ECM and the cytoskeleton, and these connections are mediated by integrins on the cell surface. In previous studies [14-16], increasing Matrigel matrix stiffness either through the addition of collagen to Matrigel or by mixing Matrigel with alginate, promoted uncontrolled growth in MCF10A cells and caused the disruption of integrin $\beta 1$ or $\beta 4$. The disordered localization of integrins observed for confined cells in this study suggests that the formation of hemidesmosomes were disrupted. However, unlike previous studies, in which a similar phenomenon was caused by changes in the biochemistry, composition, and/or mechanics of the ECM, here the Matrigel matrix was unmodified with the only other variable being the stiffer outer alginate shell.

Our RNA-seq analysis found that the expression of approximately 8000 genes was altered under physical confinement. We observed changes in expression 9 passages after removing the encapsulation, suggesting that changes in expression last for an extended duration. This result implies that confinement changes gene expression in lasting ways that prevent MCF10A cells from reverting back to their normal state. Changes in gene expression that alter the gene expression regulatory state that cells are present in can have the potential to lock in new cellular states [48]. This type of change in expression could be a key factor in allowing MCF10A-PC to "remember" the confinement and continue to generate excess growth signaling for uncontrolled growth and invasion even after removal from the microcapsules. Based on the RNA-seq, we hypothesize that epigenetic alterations in gene expression in the confined MCF10A cells activates signaling pathways, such as IGF and MAPK, which then converts the MCF10A cells to a stable transformed tumor-like state. This result provides a different aspect to understand how the physical confinement induces malignant transformation comparing with previous studies by increasing matrix stiffness which mainly focuses on mechanotransduction signaling pathway [14-16,49,50]. The mechanotransduction pathway indeed plays an important role in uncontrolled cell growth. However, our RNA-seq data indicated that this pathway was not upregulated under physical confinement. Moreover, the inhibitors for FAK, Src kinase and Rac1 targeting this pathway failed to stop the growth in microcapsules (Fig. S14b), suggesting that mechanotransduction is not the main cause of the transformation. In addition, while engineered MCF10A cells lost the expression of cytoplasmic tail of integrin $\beta 1$ or $\beta 4$, these cells still continuously grew in microcapsules (Figs. S14c-d). All these results suggest that the mechanotransduction is unlikely activated for proliferation in microcapsules. 
The in-vivo xenograft data indicates that the confinement-induced changes in MCF10A cellular behavior observed in vitro could potentially result in malignant carcinomas. In normal mammary gland architecture or in DCIS, tubules are composed of a single, proliferative layer of polygonal cells lining a central lumen [2,51]. On the other hand, nests and trabeculae, which are solid structures without lumens, were observed in MCF10A cells exposed to physical confinement (Fig. S21) and are characteristic of invasive ductal carcinoma. Moreover, the cells forming nests and trabeculae were often larger with more cytoplasm than the ones forming tubules. These cells are less similar to the normal mammary epithelial cells and probably reflect de-differentiation in the xenograft. Also, some of these nests developed areas of central necrosis similar to more aggressive tumors. Ordinarily, MCF10A cells do not grow or survive in in vivo xenografts. In fact, in order to form malignant MCF10A cell lines (e.g. MCF10AT), they typically must be transformed to stably overexpress the H-Ras gene. Importantly, these transformed MCF10A cells tend to form tumors in mice more slowly (over $\sim 3$ months vs. 40 days) and at a lower rate ( $40 \%$ vs. $90 \%$ ) compared to MCF10A cells grown in our microcapsules [11].

In conclusion, not only does this study provide interesting insights into how physical confinement of the breast epithelium can induce tumor formation, but also, the mini-tumors formed in microcapsules could be useful for breast cancer research and treatment development. The high-throughput nature of the electrospray encapsulation technique allows hundreds or thousands of microcapsules to be rapidly produced for drug screening with tumor pressure $[36,52,53]$ or other industrial applications.

\section{Supplementary Material}

Refer to Web version on PubMed Central for supplementary material.

\section{Acknowledgements}

The authors thank E. Rice for the technical assistance with preparing RNA for sequencing. This work was supported by the US National Institutes of Health (NIH)/ National Cancer Institute (Grant 1R03EB020910-01 for M.M., R01CA182413 and R01CA197160 for A.Y.N., R01CA221346 for M.W. and M.S.H.) and New York State Stem Cell Science (NYSTEM) (Grant N13S-002 for A.Y.N. and T.S.) The work used services provided by the RNA Sequencing Core (RSC) and the Biotechnology Resource Center (BRC) at Cornell University in genomic and imaging shared facilities, which are partially fund by NIH grants U54 HD076210 and 1S10RR025502.

\section{References}

[1]. DeSantis CE, Ma J, Goding Sauer A, Newman LA, Jemal A, Breast cancer statistics, 2017, racial disparity in mortality by state, CA, Cancer J. Clin 67 (2017) 439-448, 10.3322/caac.21412.

[2]. Page DL, Lagios MD, Pathology and clinical evolution of ductal carcinoma in situ (DCIS) of the breast, Cancer Lett. 86 (1994) 1-4, 10.1016/0304-3835(94)90173-2. [PubMed: 7954344]

[3]. Ellis IO, Intraductal proliferative lesions of the breast: Morphology, associated risk and molecular biology, Mod. Pathol 23 (Suppl 2) (2010) S1-S7, 10.1038/modpathol.2010.56. [PubMed: 20436497]

[4]. Silverstein MJ, Lagios MD, Craig PH, Waisman JR, Lewinsky BS, Colburn WJ, Poller DN, A prognostic index for ductal carcinoma in situ of the breast, Cancer 77 (1996) 2267-2274, 10.1002/(SICI)1097-0142(19960601)77:11<2267::AID-CNCR13>3.0.CO;2-V. [PubMed: 8635094] 
[5]. Place AE, Jin Huh S, Polyak K, The microenvironment in breast cancer progression: Biology and implications for treatment, Breast Cancer Res. 13 (2011) 227, 10.1186/bcr2912. [PubMed: 22078026]

[6]. Chavez KJ, Garimella SV, Lipkowitz S, Triple negative breast cancer cell lines: One tool in the search for better treatment of triple negative breast cancer, Breast Dis. 32 (2011) 35-48, 10.3233/ BD-2010-0307.

[7]. Bauer KR, Brown M, Cress RD, Parise CA, Caggiano V, Descriptive analysis of estrogen receptor (ER)-negative, progesterone receptor (PR)-negative, and HER2-negative invasive breast cancer, the so-called triple-negative phenotype, Cancer 109 (2007) 1721-1728, 10.1002/cncr.22618. [PubMed: 17387718]

[8]. Debnath J, Muthuswamy SK, Brugge JS, Morphogenesis and oncogenesis of MCF-10A mammary epithelial acini grown in three-dimensional basement membrane cultures, Methods 30 (2003) 256-268 doi:S104620230300032X [pii]. [PubMed: 12798140]

[9]. Qu Y, Han B, Yu Y, Yao W, Bose S, Karlan BY, Giuliano AE, Cui X, Evaluation of MCF10A as a reliable model for normal human mammary epithelial cells, PLoS One 10 (2015) 1-16, 10.1371/ journal.pone.0131285.

[10]. Santner SJ, Dawson PJ, Tait L, Soule HD, Eliason J, Mohamed AN, Wolman SR, Heppner GH, Miller FR, Malignant MCF10CA1 cell lines derived from premalignant human breast epithelial MCF10AT cells, Breast Canc. Res. Treat 65 (2001) 101-110 http://www.ncbi.nlm.nih.gov/ pubmed/11261825, Accessed date: 26 March 2018.

[11]. Dawson PJ, Wolman SR, Tait L, Heppner GH, Miller FR, MCF10AT: A model for the evolution of cancer from proliferative breast disease, Am. J. Pathol 148 (1996) 313-319 http:// www.ncbi.nlm.nih.gov/pubmed/8546221 , Accessed date: 26 March 2018. [PubMed: 8546221]

[12]. Visvader JE, Keeping abreast of the mammary epithelial hierarchy and breast tumorigenesis, Genes Dev. 23 (2009) 2563-2577, 10.1101/gad.1849509. [PubMed: 19933147]

[13]. Polyak K, Breast cancer: Origins and evolution, J. Clin. Investig 117 (2007) 3155-3163, 10.1172/ JCI33295. [PubMed: 17975657]

[14]. Levental KR, Yu H, Kass L, Lakins JN, Egeblad M, Erler JT, Fong SFT, Csiszar K, Giaccia A, Weninger W, Yamauchi M, Gasser DL, Weaver VM, Matrix crosslinking forces tumor progression by enhancing integrin signaling, Cell 139 (2009) 891-906, 10.1016/ j.cell.2009.10.027. [PubMed: 19931152]

[15]. Paszek M, Zahir N, Johnson K, Lakins J, Rozenberg G, Gefen A, Reinhart-King C, Margulies S, Dembo M, Boettiger D, Hammer DAD, Weaver V, Tensional homeostasis and the malignant phenotype, Cancer Cell 8 (2005) 241-254, 10.1016/j.ccr.2005.08.010 doi:S1535-6108(05)00268-0 [pii]. [PubMed: 16169468]

[16]. Chaudhuri O, Koshy ST, Branco da Cunha C, Shin J-W, Verbeke CS, Allison KH, Mooney DJ, Extracellular matrix stiffness and composition jointly regulate the induction of malignant phenotypes in mammary epithelium, Nat. Mater 13 (2014) 1-35, 10.1038/nmat4009. [PubMed: 24343503]

[17]. Lu Y-C, Song W, An D, Kim BJ, Schwartz R, Wu M, Ma M, Designing compartmentalized hydrogel microparticles for cell encapsulation and scalable 3D cell culture, J. Mater. Chem. B 3 (2015) 353-360 http://pubs.rsc.org/en/content/articlehtml/2015/tb/c4tb01735h. [PubMed: 32262039]

[18]. Rakha EA, El-Sayed ME, Lee AHS, Elston CW, Grainge MJ, Hodi Z, Blamey RW, Ellis IO, Prognostic significance of Nottingham histologic grade in invasive breast carcinoma, J. Clin. Oncol 26 (2008) 3153-3158, 10.1200/JCO.2007.15.5986. [PubMed: 18490649]

[19]. Soofi SS, Last JA, Liliensiek SJ, Nealey PF, Murphy CJ, The elastic modulus of Matrigel as determined by atomic force microscopy, J. Struct. Biol 167 (2009) 216-219, 10.1016/ j.jsb.2009.05.005. [PubMed: 19481153]

[20]. Samani A, Zubovits J, Plewes D, Elastic moduli of normal and pathological human breast tissues: An inversion-technique-based investigation of 169 samples, Phys. Med. Biol 52 (2007) 15651576, 10.1088/0031-9155/52/6/002. [PubMed: 17327649]

[21]. V Liberti M, Locasale JW, The warburg effect: How does it benefit cancer cells? Trends Biochem. Sci 41 (2016) 211-218, 10.1016/j.tibs.2015.12.001. [PubMed: 26778478] 
[22]. Miura T, Tanaka R, In vitro Vasculogenesis models revisited measurement of VEGF diffusion in Matrigel, Math. Model. Nat. Phenom 4 (2009) 118-130, 10.1051/mmnp/20094404.

[23]. Chai Y, Mei L-H, Lin D-Q, Yao S-J, Diffusion coefficients in intrahollow calcium alginate microcapsules, J. Chem. Eng. Data 49 (2004) 475-478, 10.1021/je034132u.

[24]. Tsai JH, Yang J, Epithelial-mesenchymal plasticity in carcinoma metastasis, Genes Dev. 27 (2013) 2192-2206, 10.1101/gad.225334.113. [PubMed: 24142872]

[25]. Barnabas N, Cohen D, Phenotypic and molecular characterization of MCF10DCIS and SUM breast cancer cell lines, Int. J. Breast Cancer 2013 (2013) 872743, 10.1155/2013/872743. [PubMed: 23401782]

[26]. Ashburner M, Ball CA, Blake JA, Botstein D, Butler H, Cherry JM, Davis AP, Dolinski K, Dwight SS, Eppig JT, Harris MA, Hill DP, Issel-Tarver L, Kasarskis A, Lewis S, Matese JC, Richardson JE, Ringwald M, Rubin GM, Sherlock G, Gene Ontology: Tool for the unification of biology, Nat. Genet 25 (2000) 25-29, 10.1038/75556. [PubMed: 10802651]

[27]. Cedano Prieto DM, Cheng Y, Chang C-C, Yu J, Takada YKY, Takada YKY, Direct integrin binding to insulin-like growth factor-2 through the $\mathrm{C}$-domain is required for insulin-like growth factor receptor type 1 (IGF1R) signaling, PLoS One 12 (2017) e0184285, , 10.1371/ journal.pone.0184285. [PubMed: 28873464]

[28]. Kocatürk B, Versteeg HH, Orthotopic injection of breast cancer cells into the mammary fat pad of mice to study tumor growth, J. Vis. Exp (2015), 10.3791/51967.

[29]. McElwee JL, Mohanan S, Griffith OL, Breuer HC, Anguish LJ, Cherrington BD, Palmer AM, Howe LR, Subramanian V, Causey CP, Thompson PR, Gray JW, Coonrod SA, Identification of PADI2 as a potential breast cancer biomarker and therapeutic target, BMC Canc. 12 (2012) 500, 10.1186/1471-2407-12-500.

[30]. Balzer EM, Tong Z, Paul CD, Hung W-C, Stroka KM, Boggs AE, Martin SS, Konstantopoulos K, Physical confinement alters tumor cell adhesion and migration phenotypes, FASEB J. 26 (2012) 4045-4056, 10.1096/fj.12-211441. [PubMed: 22707566]

[31]. Moriarty RA, Stroka KM, Physical confinement alters sarcoma cell cycle progression and division, Cell Cycle 17 (2018) 2360-2373, 10.1080/15384101.2018.1533776. [PubMed: 30304981]

[32]. Reynolds DS, Bougher KM, Letendre JH, Fitzgerald SF, Gisladottir UO, Grinstaff MW, Zaman MH, Mechanical confinement via a PEG/Collagen interpenetrating network inhibits behavior characteristic of malignant cells in the triple negative breast cancer cell line MDA.MB.231, Acta Biomater. 77 (2018) 85-95 10.1016/j.actbio.2018.07.032. [PubMed: 30030173]

[33]. Djomehri SI, Burman B, Gonzalez ME, Takayama S, Kleer CG, A reproducible scaffold-free 3D organoid model to study neoplastic progression in breast cancer, J. Cell Commun. Signal 13 (2019) 129-143, 10.1007/s12079-018-0498-7. [PubMed: 30515709]

[34]. Boyd NF, Guo H, Martin LJ, Sun L, Stone J, Fishell E, Jong RA, Hislop G, Chiarelli A, Minkin $\mathrm{S}$, Yaffe MJ, Mammographic density and the risk and detection of breast cancer, N. Engl. J. Med 356 (2007) 227-236, 10.1056/NEJMoa062790 doi:356/3/227 [pii]. [PubMed: 17229950]

[35]. Boyd NF, Martin LJ, Rommens JM, Paterson AD, Minkin S, Yaffe MJ, Stone J, Hopper JL, Mammographic Density: A Heritable Risk Factor for Breast Cancer, Humana Press, 2009, pp. 343-360, , 10.1007/978-1-60327-492-0_15.

[36]. Alessandri K, Sarangi BR, Gurchenkov VV, Sinha B, Kießling TR, Fetler L, Rico F, Scheuring S, Lamaze C, Simon A, Geraldo S, Vignjevic D, Doméjean H, Rolland L, Funfak A, Bibette J, Bremond N, Nassoy P, Kiessling TR, Fetler L, Rico F, Scheuring S, Lamaze C, Simon A, Geraldo S, Vignjevic D, Domejean H, Rolland L, Funfak A, Bibette J, Bremond N, Nassoy P, Cellular capsules as a tool for multicellular spheroid production and for investigating the mechanics of tumor progression in vitro, Proc. Natl. Acad. Sci. USA 110 (2013) 14843-14848, 10.1073/Pnas.1309482110. [PubMed: 23980147]

[37]. Guo M, Pegoraro AF, Mao A, Zhou EH, Arany PR, Han Y, Burnette DT, Jensen MH, Kasza KE, Moore JR, Mackintosh FC, Fredberg JJ, Mooney DJ, Lippincott-Schwartz J, Weitz DA, Cell volume change through water efflux impacts cell stiffness and stem cell fate, Proc. Natl. Acad. Sci. U.S.A 114 (2017) E8618 LP-E8627, 10.1073/pnas.1705179114. [PubMed: 28973866] 
[38]. Stroka KM, Jiang H, Chen S-H, Tong Z, Wirtz D, Sun SX, Konstantopoulos K, Water permeation drives tumor cell migration in confined microenvironments, Cell 157 (2014) 611-623 10.1016/ j.cell.2014.02.052. [PubMed: 24726433]

[39]. Plant AL, Bhadriraju K, Spurlin TA, Elliott JT, Cell response to matrix mechanics: Focus on collagen, Biochim. Biophys. Acta Mol. Cell Res 1793 (2009) 893-902 10.1016/ j.bbamcr.2008.10.012.

[40]. Elliott JT, Woodward JT, Langenbach KJ, Tona A, Jones PL, Plant AL, Vascular smooth muscle cell response on thin films of collagen, Matrix Biol. 24 (2005) 489-502 10.1016/ j.matbio.2005.07.005. [PubMed: 16153814]

[41]. Grundy TJ, De Leon E, Griffin KR, Stringer BW, Day BW, Fabry B, Cooper-White J, O’Neill GM, Differential response of patient-derived primary glioblastoma cells to environmental stiffness, Sci. Rep 6 (2016) 23353 10.1038/srep23353. [PubMed: 26996336]

[42]. Long R, Hall MS, Wu M, Hui C-Y, Effects of gel thickness on microscopic indentation measurements of gel modulus, Biophys. J 101 (2011) 643-650 10.1016/j.bpj.2011.06.049. [PubMed: 21806932]

[43]. Aung A, Seo YN, Lu S, Wang Y, Jamora C, del Álamo JC, Varghese S, 3D traction stresses activate protease-dependent invasion of cancer cells, Biophys. J 107 (2014) 2528-2537, 10.1016/ j.bpj.2014.07.078. [PubMed: 25468332]

[44]. Rudnicki MS, Cirka HA, Aghvami M, Sander EA, Wen Q, Billiar KL, Nonlinear strain stiffening is not sufficient to explain how far cells Can Feel on fibrous protein gels, Biophys. J 105 (2013) 11-20, 10.1016/j.bpj.2013.05.032. [PubMed: 23823219]

[45]. Poincloux R, Collin O, Lizárraga F, Romao M, Debray M, Piel M, Chavrier P, Contractility of the cell rear drives invasion of breast tumor cells in 3D Matrigel, Proc. Natl. Acad. Sci. U.S.A 108 (2011) 1943, 10.1073/pnas.1010396108 LP - 1948. [PubMed: 21245302]

[46]. Wang H, Lacoche S, Huang L, Xue B, Muthuswamy SK, Rotational motion during threedimensional morphogenesis of mammary epithelial acini relates to laminin matrix assembly, Proc. Natl. Acad. Sci. USA 110 (2013) 163-168, 10.1073/pnas.1201141110. [PubMed: 23248267]

[47]. Underwood JM, Imbalzano KM, Weaver VM, Fischer AH, Imbalzano AN, Nickerson JA, The ultrastructure of MCF-10A acini, J. Cell. Physiol 208 (2006) 141-148, 10.1002/Jcp.20639. [PubMed: 16607610]

[48]. Pisco AO, d'Herouel AF, Huang S, Conceptual Confusion: The Case of Epigenetics, BioRxiv (2016), 10.1101/053009 053009.

[49]. Huang G, Li F, Zhao X, Ma Y, Li Y, Lin M, Jin G, Lu TJ, Genin GM, Xu F, Functional and biomimetic materials for engineering of the three-dimensional cell microenvironment, Chem. Rev 117 (2017) 12764-12850, 10.1021/acs.chemrev.7b00094. [PubMed: 28991456]

[50]. Rice AJ, Cortes E, Lachowski D, Cheung BCH, Karim SA, Morton JP, del Rio Hernandez A, Matrix stiffness induces epithelial-mesenchymal transition and promotes chemoresistance in pancreatic cancer cells, Oncogenesis 6 (2017) e352 10.1038/oncsis.2017.54. [PubMed: 28671675]

[51]. Elston CW, The assessment of histological differentiation in breast cancer, ANZ J. Surg 54 (1984) 11-15, 10.1111/j.1445-2197.1984.tb06677.x.

[52]. Anderson ARA, Weaver AM, Cummings PT, Quaranta V, Tumor morphology and phenotypic evolution driven by selective pressure from the microenvironment, Cell 127 (2006) 905-915, 10.1016/J.CELL.2006.09.042. [PubMed: 17129778]

[53]. Ariffin AB, Forde PF, Jahangeer S, Soden DM, Hinchion J, Releasing pressure in tumors: What do we know so far and where do we go from here? A review, Cancer Res. 74 (2014) 2655-2662, 10.1158/0008-5472.CAN-13-3696. [PubMed: 24778418] 
(a)

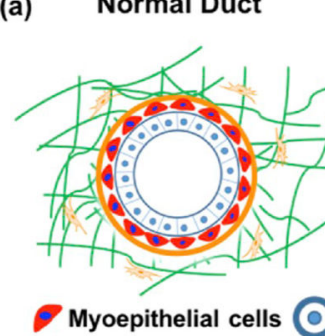

(c)
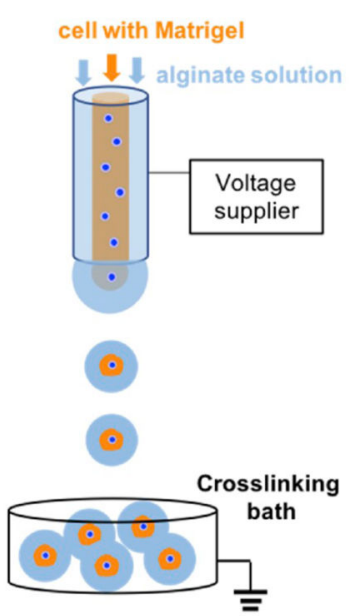

(f) microcapsules

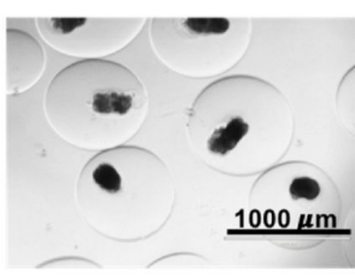

Normal Duct with Higher Mammographic Density

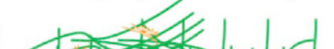

Duc In Situ (DCIS)

(b) (d1)

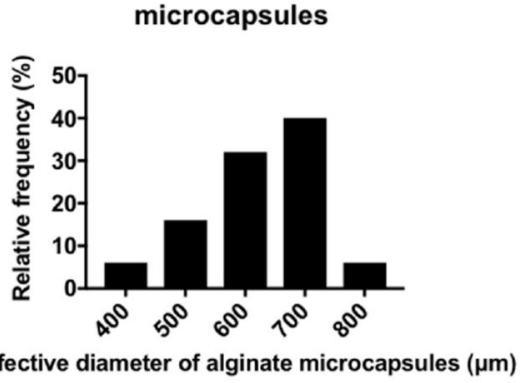

(e1)

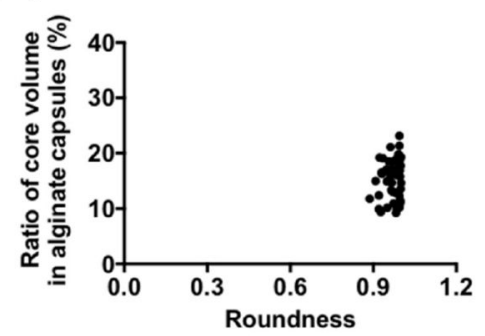

(d2)

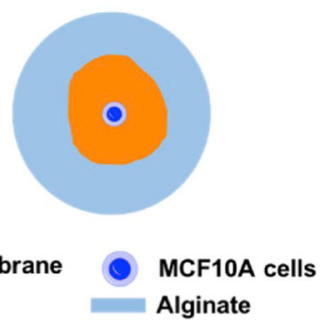

Large $(\sim 600 \mu \mathrm{m})$ core capsules

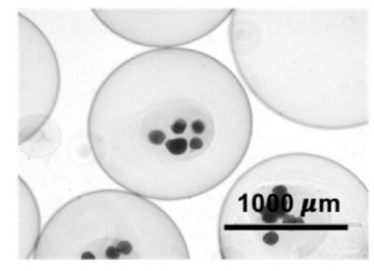

(g)

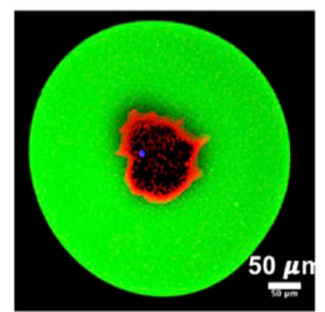

Large $(\sim 600 \mu \mathrm{m})$ core capsules

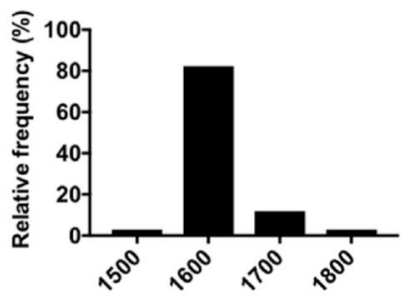

Effective diameter of alginate capsule $(\mu \mathrm{m})$

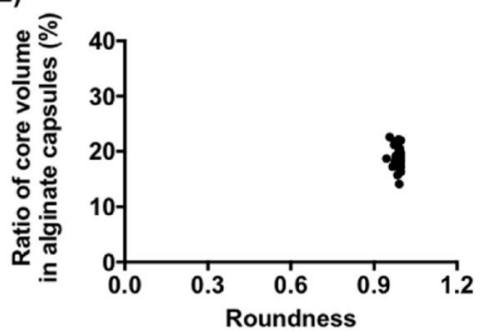

Fig. 1.

Mammary tumorigenesis under physical confinement and characterization of core-shell hydrogel microcapsules (a) Schematic illustrations of mammary epithelium with increasing mammographic density as a risk factor for breast cancer initiation and progression. (b) Schematic of a core-shell microcapsule encapsulating a single MCF10A cell in basement membrane matrix confined by a stiffer hydrogel layer to simulate the in-vivo mammary epithelium microenvironment under high mammographic density. (c) The core-shell microcapsules were produced by a two-fluidic electrostatic co-spraying technique. The shell fluid is an alginate solution, and the core fluid is cold Matrigel solution with MCF10A cells. These core and shell fluids were co-sprayed into a room temperature crosslinking bath for gelation. (d) The histogram of size distribution for core-shell microcapsules $(621.5 \pm 13.4$ $\mu \mathrm{m}, \mathrm{n}=50$, pooled from 3 independent experiments) and large core capsules $(1601.4 \pm 10.2$ 
$\mu \mathrm{m}, \mathrm{n}=34$, pooled from 3 independent experiments). (e) The ratio of core volume is $15.5 \pm$ $0.5 \%$ for microcapsules $(n=50)$ and $18.6 \pm 0.6 \%$ for large core capsules $(n=34)$. (f) MCF10A cells were encapsulated in microcapsules and large core capsules after being cultured for 30 days. (g) A MCF10A cell was encapsulated in fluorescently labeled alginate shell (green). The laminin (red) which is the primary component in Matrigel was stained by its antibody; the MCF10A cell was stained by Hoechst 33342 (blue). 
(a)

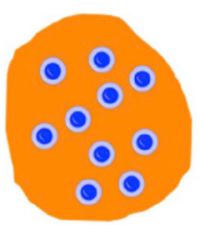

(b)

(c)
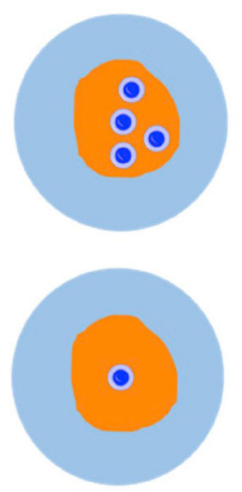

Day 0
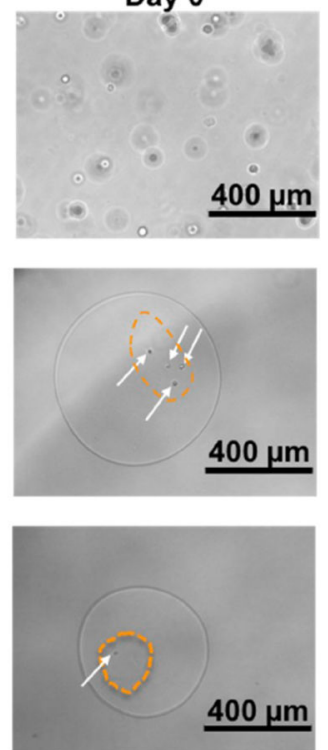

Day 21
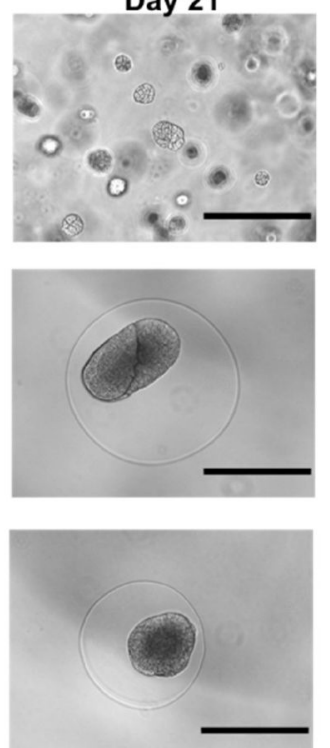

Nucleus/F-actin
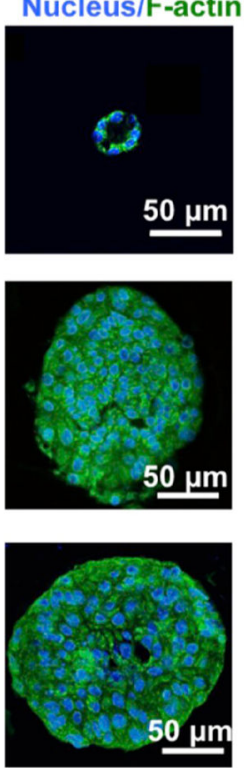

$\beta 1$ integrin
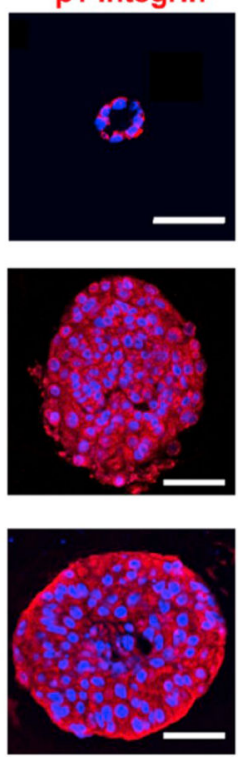

Fig. 2.

Malignant transformation of mammary epithelium under confinement of core-shell microcapsules (a) MCF10A cells form acini after being cultured in bulk Matrigel for 21 days. Cytoskeleton, F-actin (green) and integrin $\beta 1$ (red) were immunofluorescently stained. (b) Four MCF10A cells in Matrigel core within a microcapsule underwent uncontrolled growth. The F-actin(green) became blurred and the surface localization of integrin $\beta 1$ (red) was disrupted. (c) A single MCF10A cell was confined in a core-shell microcapsule, exhibiting similar disruption of integrin $\beta 1$ (red) localization. 
(a)

(c)

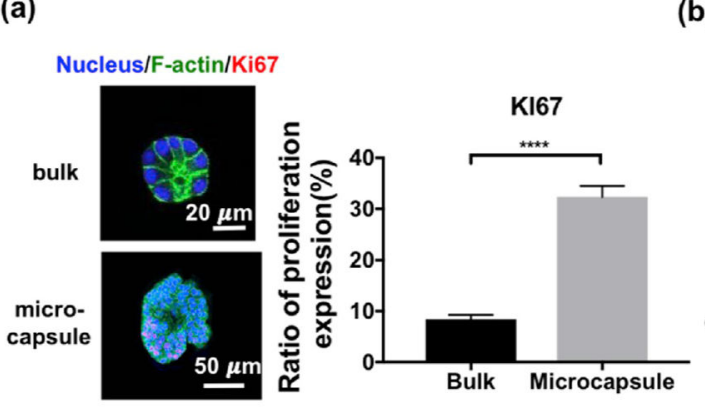

(b)

Nucleus/F-actin/ Cleaved Caspase-3
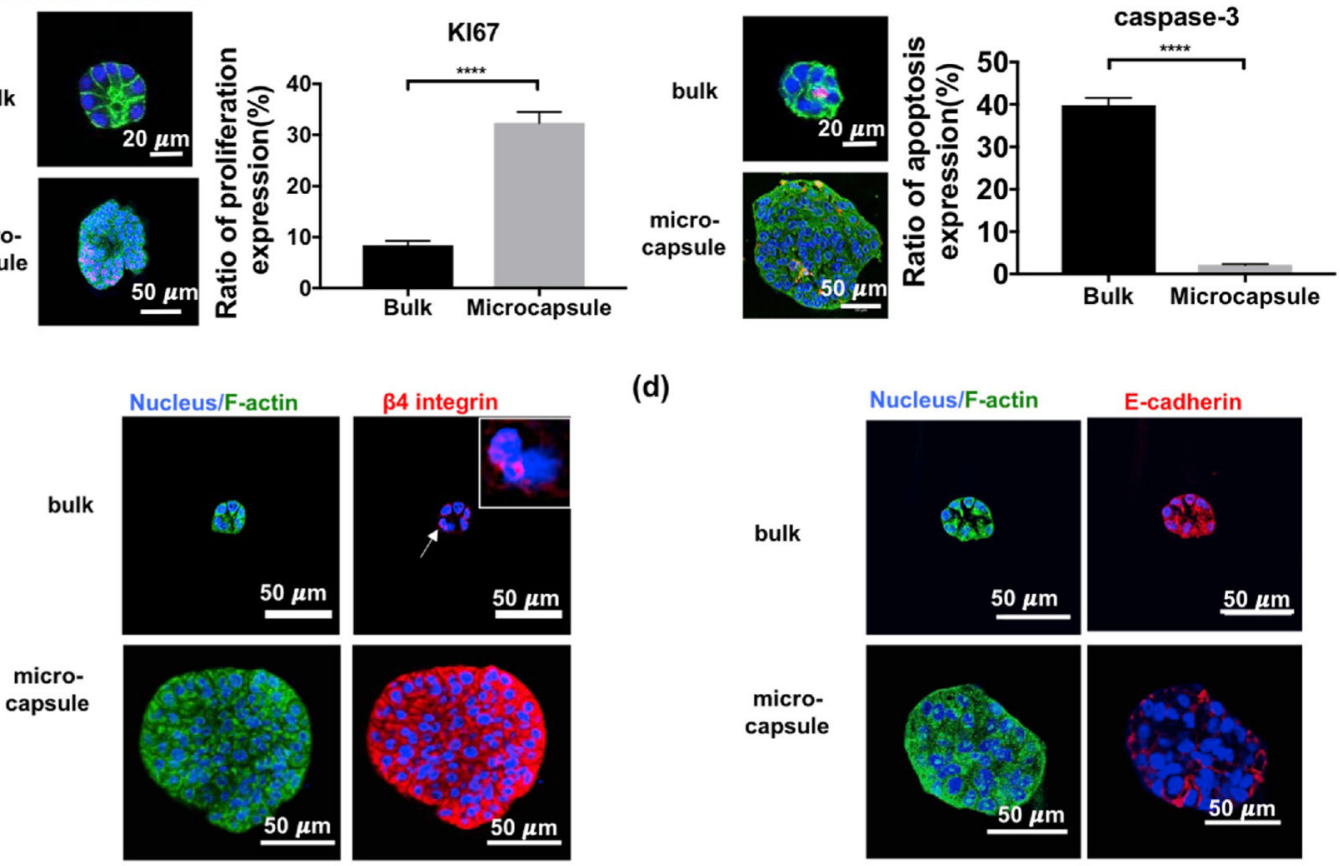

(d)

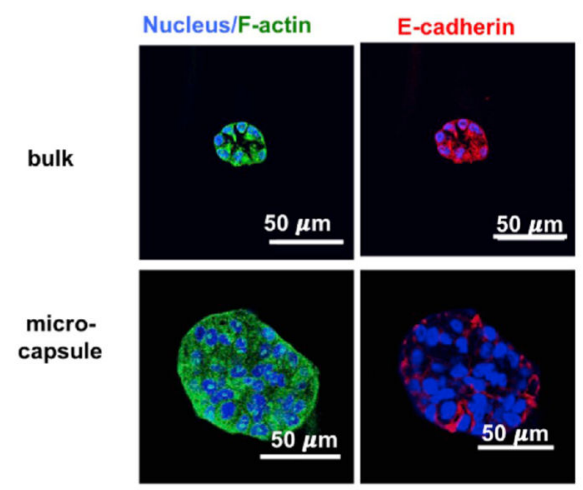

Fig. 3.

Characterization of the malignant behavior of confined MCF10A cells. (a) Expression of KI67 (red), a proliferation marker, in acini grown from bulk or aggregates from microcapsules. ( $\mathrm{n}=427$ for bulk and 259 for microcapsules, pooled from 6 independent experiments, $\mathrm{F}=62.68, \mathrm{df}=1, \mathrm{p}<0.0001$ by two-way ANOVA) (b) Expression of cleaved caspase-3 (red), an apoptosis marker, in acini grown from bulk or aggregates from microcapsules. $(\mathrm{n}=321$ for bulk and 248 for microcapsules, pooled from 6 independent experiments, $\mathrm{F}=151.2$, $\mathrm{df}=1, \mathrm{p}<0.0001$ ) (c) Staining of $\mathrm{F}$-actin (green) and integrin $\beta 4$ (red) revealing the disruption of integrin localization in confined cells from microcapsules. (d) Staining of E-cadherin (red) which was fully expressed in bulk acini but mostly lost in cell aggregates from microcapsules, a suggestion of EMT. (e) An invasion assay: acini from 
bulk Matrigel maintained its structure after 9 days of culture in collagen, but the aggregates from microcapsules grew and started to invade into the surrounding collagen matrix after 2 days. (f) Quantification of the invasion assay ( $\mathrm{n}=130$ for bulk and 116 for microcapsules, pooled from 3 independent experiments, $\mathrm{t}=14.88, \mathrm{df}=4.181, \mathrm{p}<0.0001$ by Welchcorrected $t$-test). 
(a)

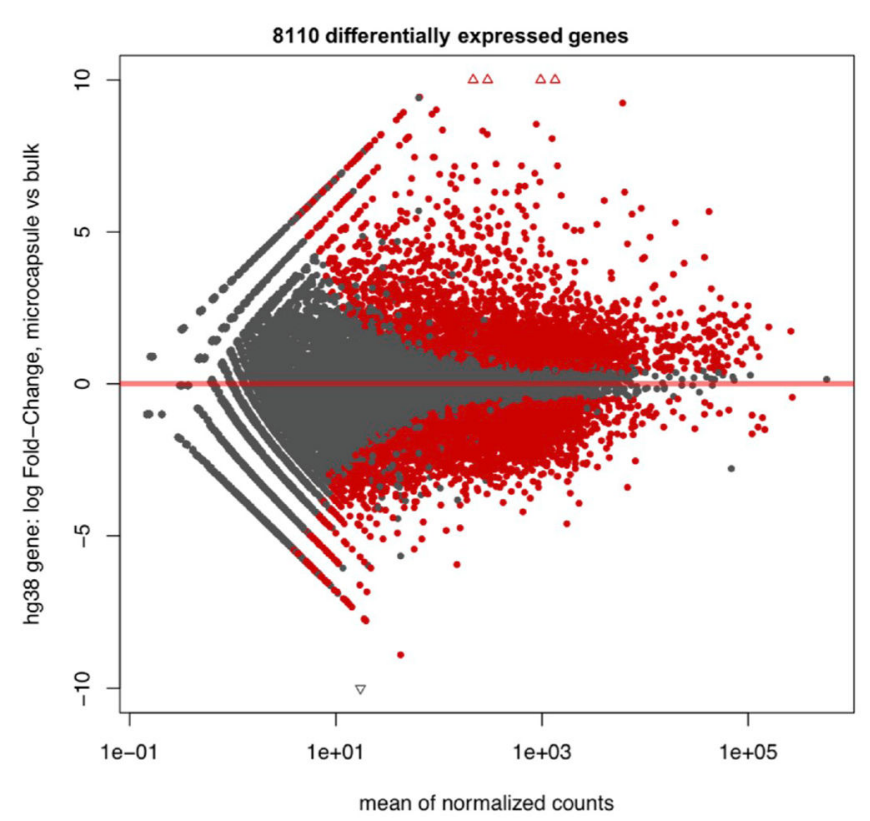

(b)
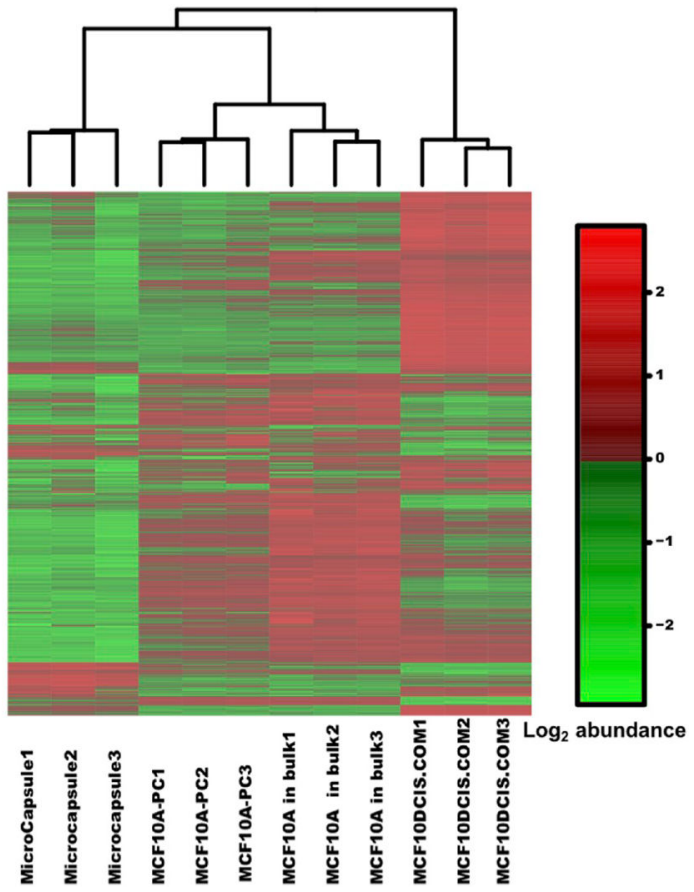

Fig. 4.

RNA-seq of cells from microcapsules and from bulk. (a) The MA plot for differential gene expression in fold-change of confined cells in microcapsules over cells in bulk Matrigel. There are 8110 genes which are differentially expressed in microcapsules comparing with bulk. (adjusted p < 0.01) (b) The heat map of normalized RNA-seq data from 12 samples among 4 different groups: cells from microcapsules as well as MCF10A-PC (9th passage), normal MCF10A cells and MCF10DCIS.COM cells in bulk Matrigel (3 replicates for each group). Moreover, 5000 transcripts with highest variances were utilized to depict the heat map. In each group, all the samples were clustered together suggesting the consistent gene expression. 


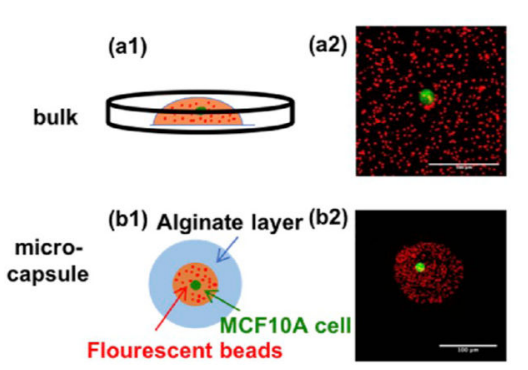

(e)
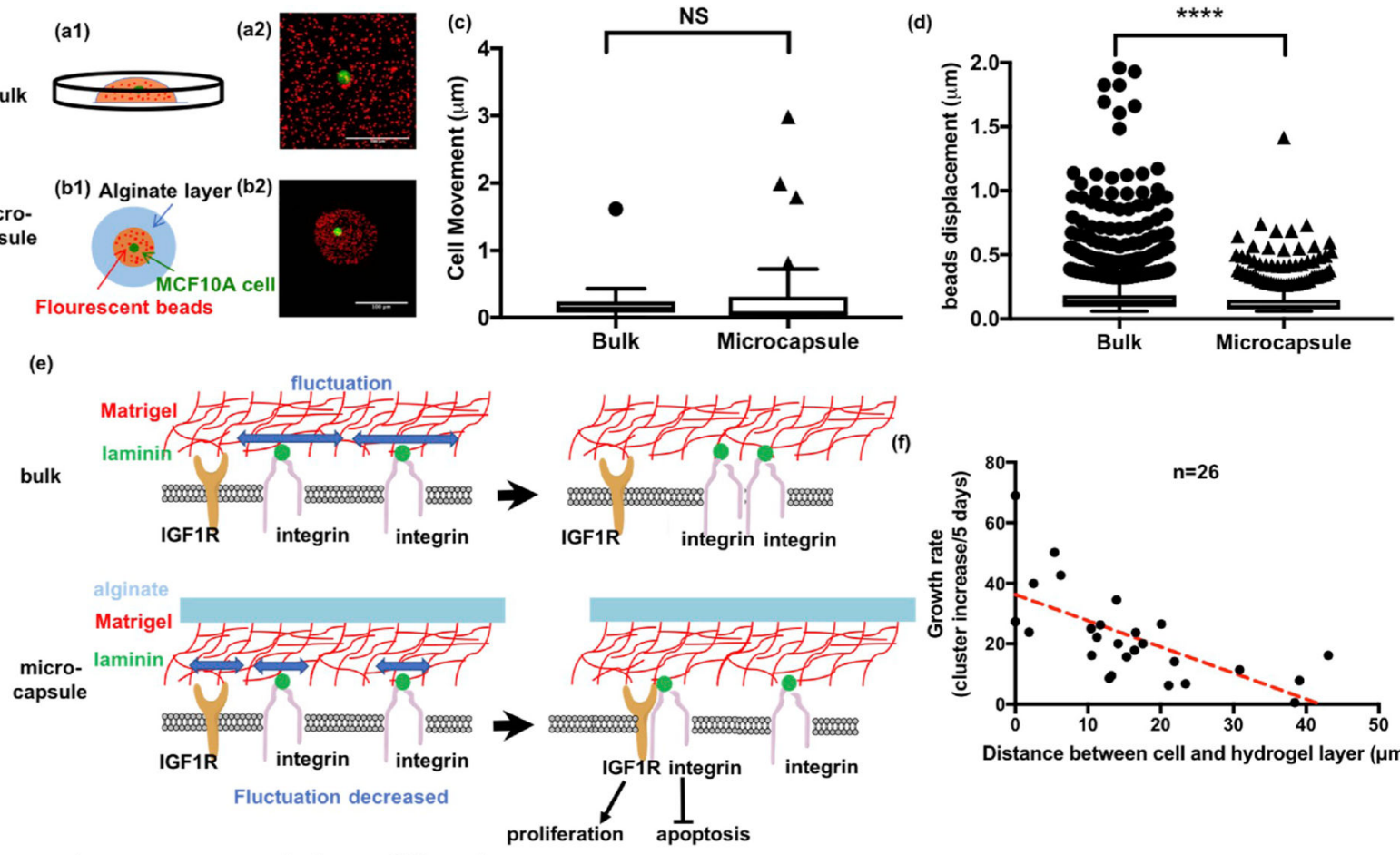

Large core capsule (core $600 \mu \mathrm{m})$

(g1)

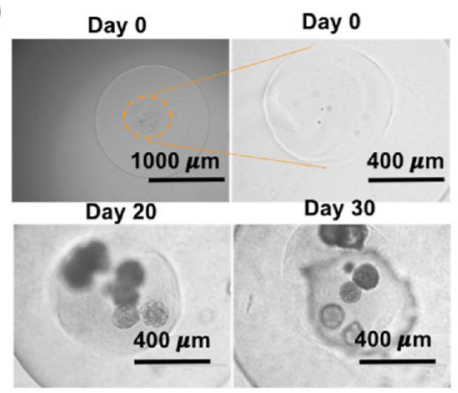

(g2)
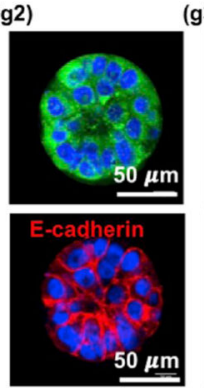

F-actin/Nucleus

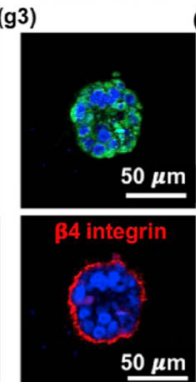

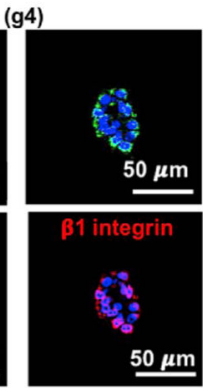

Fig. 5.

Confinement restricts matrix fluctuation to disrupt acini formation. (a-d) Study of matrix fluctuation using fluorescent beads tracking. (a) Schematic and the z-projection of fluorescent beads and a MCF10A cell in bulk Matrigel. (Red: fluorescent beads; Green: GFP-expressing MCF10A cells.) (b) Schematic and z-projection for a single MCF10A cell in Matrigel with fluorescent beads encapsulated in an alginate core-shell microcapsule. Scale bars are $100 \mu \mathrm{m}$. (c) Cells behaved similarly in bulk as in microcapsules. ( $\mathrm{n}=40,56$ pooled from 5 independent experiments, $\mathrm{t}=4.75, \mathrm{df}=870.7, \mathrm{p}=0.2993$ by Welch-corrected $t$-test) (d) Bead displacement was significantly smaller in microcapsules than in bulk where beads were freely moved without confinement. ( $\mathrm{n}=8113,732$ pooled from 5 experiments, $\mathrm{t}$ $=1.044, \mathrm{df}=84.6, \mathrm{p}<0.0001$ by Welch-corrected $t$-test) (e) Schematic illustration for how confinement might disrupt the formation of hemidesmosomes while promoting the integrin binding to insulin-like growth factor receptor to induce uncontrolled growth. (f) The relationship for growth rate versus the distance between the cell and the alginate layer. $(\mathrm{g})$ When the core size increased to $\sim 600 \mu \mathrm{m}$, the confinement effect diminished. The confined 
cells formed acini again in these capsules, integrin $\beta 1$ (red) and $\beta 4$ (red) were localized on the surface and E-cadherin (red) was fully expressed. 
(a)

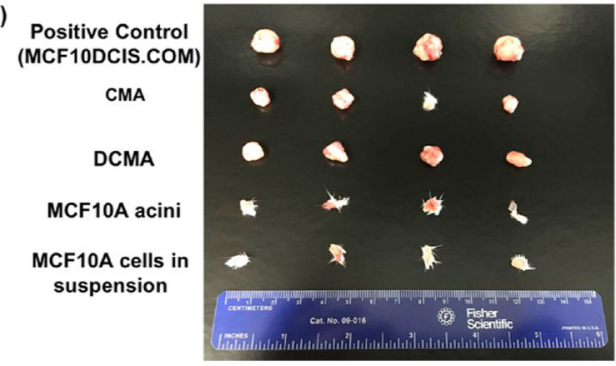

(c)

Positive Control (MCF10DCIS.COM)
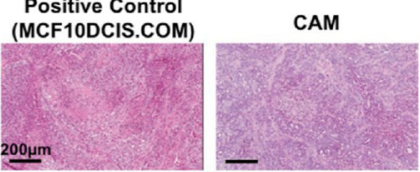

Fig. 6. (b)

\begin{tabular}{|c|c|c|}
\hline & number of tumor formation & Average weight (g) \\
\hline Positive Control (MCF10DCIS.COM) & 10 of 10 & $0.99+-0.37$ \\
\hline CMA & 9 of 10 & $0.57+-0.37$ \\
\hline DCMA & 7 of 8 & $0.49+-0.30$ \\
\hline MCF10A acini & 0 of 8 & $0.00+-0.00$ \\
\hline MCF10A cells in suspension & 0 of 10 & $0.00+-0.00$ \\
\hline
\end{tabular}

(d) tumor grade

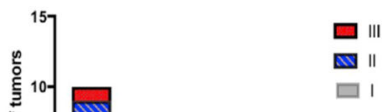

$\square$ ।

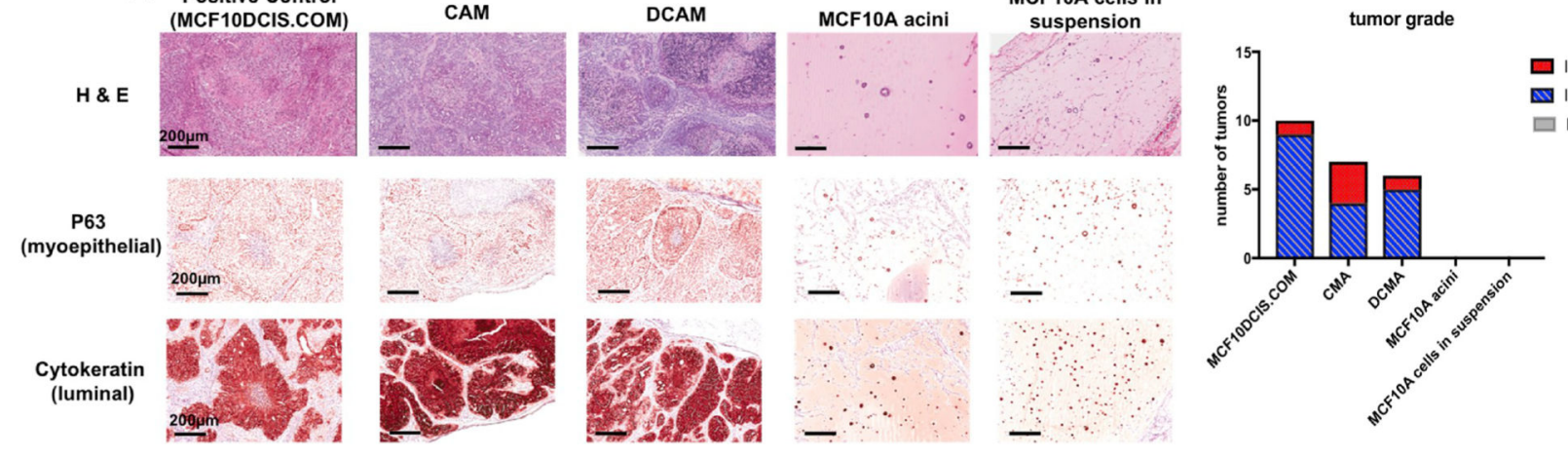

In-vivo xenograft and characterization (a) Among the five different groups (i.e.

MCF10DCIS.COM, confined MCF10A cell aggregates or CMA, confined MCF10A single

cells or DCMA, MCF10A acini and single MCF10A cells). that were injected into

mammary fat of Scid-beige mice for xenograft $(n=10)$, only MCF10DCIS.COM and CMA, or DCMA formed carcinomas. (b) Rate of tumor formation and the tumor weights from the five groups. (c) H\&E and immunohistochemistry staining for all the five groups from xenograft. Differentiation markers, p63 (myoepithelial) and cytokeratin (luminal) markers in mammary epithelium were characterized. (d) The xenograft tumors were analyzed as carcinomas and graded by tumor size, necrosis, tubules and mitotic rate. 